\title{
TOLNET OZONE LIDAR INTERCOMPARISON DURING THE DISCOVER-AQ AND FRAPPÉ CAMPAIGNS
}

\author{
Michael J. Newchurch ${ }^{1 *}$, Raul J. Alvarez II $^{2}$, Timothy A. Berkoff ${ }^{3}$, William Carrion ${ }^{4}$, Russell J. \\ DeYoung $^{3}$, Rene Ganoe ${ }^{5}$, Guillaume Gronoff ${ }^{3}$, Guillaume Kirgis ${ }^{2,6}$, Shi Kuang ${ }^{1}$, Andy O. Langford ${ }^{2}$, \\ Thierry Leblanc ${ }^{7}$, Thomas J. McGee ${ }^{8}$, Denis Pliutau ${ }^{5}$, Christoph Senff ${ }^{26}$, John T. Sullivan ${ }^{8}$, Grant \\ Sumnicht $^{5}$, Laurence W. Twigg ${ }^{5}$, Lihua Wang ${ }^{1}$ \\ ${ }^{1}$ University of Alabama in Huntsville,USA, *mike@nsstc.uah.edu \\ ${ }^{2}$ NOAA Earth System Research Laboratory, USA \\ ${ }^{3}$ NASA Langley Research Center, USA \\ ${ }^{4}$ Coherent Applications Inc., USA \\ ${ }^{5}$ Science Systems and Applications, Inc, USA \\ ${ }^{6}$ University of Colorado, USA \\ ${ }^{7}$ California Institute of Technology, USA \\ ${ }^{8}$ NASA Goddard Space Flight Center, USA
}

\begin{abstract}
The Tropospheric Ozone Lidar Network (TOLNet) is a unique network of lidar systems that measure atmospheric profiles of ozone and aerosols, to contribute to air-quality studies, atmospheric modeling, and satellite validation efforts. The accurate characterization of these lidars is of critical interest, and is necessary to determine cross-instrument calibration uniformity. From July to August 2014, three lidars, the TROPospheric OZone (TROPOZ) lidar, the Tunable Optical Profiler for Aerosol and oZone (TOPAZ) lidar, and the Langley Mobile Ozone Lidar (LMOL), of TOLNet participated in the "Deriving Information on Surface conditions from Column and Vertically Resolved Observations Relevant to Air Quality" (DISCOVER-AQ) mission and the "Front Range Air Pollution and Photochemistry Éxperiment" (FRAPPÉ) to measure sub-hourly ozone variations from near the surface to the top of the troposphere. Although large differences occur at few individual altitudes in the near field and far field range, the TOLNet lidars agree with each other within $\pm 4 \%$. These results indicate excellent measurement accuracy for the TOLNet lidars that is suitable for use in air-quality and ozone modeling efforts.
\end{abstract}

\section{INTRODUCTION}

The Tropospheric Ozone Lidar Network (TOLNet) is designed primarily to provide time and height measurements of ozone from near the surface to the top of the troposphere at multiple locations for satellite validation, model evaluation, and scientific research (http://wwwair.larc.nasa.gov/missions/TOLNet/). Particularly, these high-fidelity ozone measurements can serve to validate NASA's first Earth Venture Instrument mission, Tropospheric Emissions: Monitoring Pollution (TEMPO), planned to launch in 2020 or 2021. A second objective of TOLNet is to identify a brassboard ozone lidar instrument that would be suitable to populate a network to address increasing desire for ozone profiles by air-quality scientists and managers within the modeling and satellite communities.

TOLNet currently consists of five ozone lidars across the United States and one lidar in Canada: the Jet Propulsion Laboratory Table Mountain tropospheric Ozone (JPL-TMO) differential absorption lidar (DIAL), the TOPAZ lidar at NOAA's Earth System Research Laboratory (ESRL), the Rocket-city Ozone Quality Evaluation in the Troposphere $\left(\mathrm{RO}_{3} \mathrm{QET}\right)$ lidar at University of Alabama in Huntsville, TROPOZ DIAL of NASA's Goddard Space Flight Space Center (GSFC), and LMOL at NASA's Langley Research Center (LaRC), and AMOLITE lidar at Environment Canada. TOLNet also includes a modeling component at NASA Ames Research Center (ARC) and a data center at LaRC.

\section{LIDARS}

\subsection{TROPOZ at NASA's GSFC}

The transmitter for TROPOZ consists of two 50$\mathrm{Hz}$ Nd:YAG- lasers used to pump two Raman 
cells filled with Deuterium and Hydrogen gases, respectively, to generate two outgoing wavelengths at 289 and $299 \mathrm{~nm}$. The typical pulse energies are $12 \mathrm{~mJ}$ at $299 \mathrm{~nm}$ (off-line) and $16 \mathrm{~mJ}$ at $289 \mathrm{~nm}$ (on-line) [1]. The receiving system for the TROPOZ consists of a 45-cm-diameter Newtonian telescope for measuring far field and four smaller $2.5-\mathrm{cm}$ refracting telescopes to measure near field. The $45-\mathrm{cm}$ telescope has a $1.0-\mathrm{mrad}$ field of view $(\mathrm{FOV})$, and the $2.5-\mathrm{cm}$ telescopes have a much wider FOV at 10.0 mrad. In each channel, narrowband interference filters with 1-nm bandwidth are implemented to decrease the amount of ambient solar light, which improves the signal-to-noise ratio. The fundamental range resolution for data acquisition system is $15 \mathrm{~m}$ (100 ns). The relatively powerful lasers and large telescope result in ozone retrievals up to $16 \mathrm{~km}$ during daytime hours.

\subsection{TOPAZ at NOAA's ESRL}

The TOPAZ lidar is an up-looking, scanning instrument in a truck modified from an airborne DIAL system [2,3]. The lidar transmitter is based on a Ce:LiCAF laser that is pumped by a quadrupled Nd:YLF laser to produce three UV wavelengths at $333 \mathrm{~Hz}$ repetition rate tunable from $283 \mathrm{~nm}$ to $310 \mathrm{~nm}$. The actual wavelengths during the DISCOVER-AQ 2014 were 287, 291, and $294 \mathrm{~nm}$. Compared to the conventional twowavelength DIAL, the three-wavelength configuration can potentially minimize the aerosol interference by using the dual-DIAL retrieval technique [4] without assuming lidar ratio and Angström exponent.

The backscattered light is collected with a $50-\mathrm{cm}$ diameter Newtonian telescope and then split at a 1:9 ratio into near- and far-field detection channels. The FOVs of the near- and far-field channels are controlled by different-size apertures resulting in full overlap at distances of $\sim 300 \mathrm{~m}$ and $\sim 800 \mathrm{~m}$, respectively. Both channels use gated photomultipliers operated in analog mode with solar interference filters during daytime. Compared to a photoncounting signal, an analog signal is able to keep high linearity for strong signals and, therefore, is particularly suitable for near-range measurement. The two-axis scanner on the truck permits pointing the laser beam at several shallow elevation angles at a fixed, but changeable azimuth angle, typically at $2^{\mathrm{O}}, 10^{\mathrm{O}}$, and $90^{\circ}$ elevation angles that are repeated approximately every 5 minutes. The ozone profiles at these three angles are spliced together to create composite vertical profiles extending from $10 \mathrm{~m}$ to about $2.5 \mathrm{~km}$ AGL. The range resolution of the signal recording system is $6 \mathrm{~m}$. The TOPAZ lidar has a unique capability to measure the near-surface ozone above $10 \mathrm{~m}$ due to its scanning configuration.

\subsection{LMOL at NASA's LaRC}

The transmitter of LMOL consists of a diodepumped Nd:YLF laser pumping a Ce:LiCAF tunable UV laser to obtain two lasers typically at 287.1 and $292.7 \mathrm{~nm}$ with a pulse energy of $0.2 \mathrm{~mJ}$ at $500 \mathrm{~Hz}$ for each wavelength. The lidar receiver system consists of a $40-\mathrm{cm}$ telescope with a 1.4mrad FOV to measure far field and another $30-\mathrm{cm}$ telescope with same FOV to measure near field [5]. The raw lidar signals are recorded with a 7.5$\mathrm{m}$ range resolution. The LMOL data acquisition system operates in both analog and photoncounting modes. In this study, LMOL measures ozone between 0.7 and $4.5 \mathrm{~km}$. Ozone measurements for DISCOVER-AQ result from LMOL's first ever remote deployment.

\subsection{Measurement Uncertainty Budget}

Table 1 presents the estimation of measurement uncertainty budget for 5-min integration time for above three lidars. Statistical errors [6] arising from signal and background noise fluctuations are random errors and may be improved by additional average or smoothing. The uncertainty arising from aerosol interference cloud be the largest systematic error source and can be minimized by appropriate correction algorithm [1].

\section{RESULTS}

Prior to the campaign, the three TOLNet lidars were deployed next to the Boulder Atmospheric Observatory (BAO) tower $\left(40.050^{\circ} \mathrm{N}\right.$, $105.003^{\mathrm{O}} \mathrm{W}$ ) to take simultaneous measurements. They were within 600 meters of each other and were very near the same elevation.

Unlike stratospheric ozone lidars that focus on integrating hours of observations, tropospheric ozone lidars need to detect ozone variations with timescales on the order of minutes, considering 
ozone's shorter lifetime, smaller-scale transport, mixing processes within the PBL and free troposphere. Therefore, we processed all lidar data on a 5-min temporal scale (signal integration time). Rayleigh correction was performed with the same atmospheric profile from ozonesonde. Because the three lidars have different fundamental range resolutions, retrieved ozone number density values are internally interpolated on the same altitude grids with a $15-\mathrm{m}$ interval for comparison.

Table 1. Estimated uncertainties for TROPOZ, TOPAZ and LMOL measurements below $2 \mathrm{~km}$ AGL for 5-min integration time.

\begin{tabular}{|l|l|}
\hline Sources & Uncertainty \\
\hline Statistical error & $<8 \%$ \\
\hline Aerosol interference & $<12 \%$ \\
\hline $\begin{array}{l}\text { Interference by } \mathrm{SO}_{2}, \quad \mathrm{NO}_{2}, \quad \mathrm{O}_{2} \\
\text { dimmer }\end{array}$ & $<1.5 \%$ \\
\hline Differential Rayleigh scattering & $<1 \%$ \\
\hline Total & $<15 \%$ \\
\hline
\end{tabular}

TOPAZ and TROPOZ lidars were operated simultaneously at BAO during 1300 to 2135 UTC (6 hours ahead of local time, Mountain Daylight Time) on July 11 under a partly cloudy sky condition. Some bad data points due to cloud interference were filtered out. Ozone curtains from both lidars (Figures 1a and b) show a significant $(\sim 30 \%)$ ozone increase in the early afternoon. A total of 7655 TOPAZ and TROPOZ coincident pairs are constructed between 0.6 and 2 $\mathrm{km}$ AGL over this time period. The measurement differences between the two lidars are mostly within $\pm 5 \%$ at individual grids (Figure 1, c). The ozone averages measured by TROPOZ and TOPAZ were 126.8 and $128.2 \times 10^{16} \mathrm{molec} \cdot \mathrm{m}^{-3}$, respectively, with the same standard deviations, $18.8 \times 10^{16} \mathrm{molec} \cdot \mathrm{m}^{-3}$. The mean relative difference (or normalized bias) is calculated by averaging the relative difference, (TROPOZ-TOPAZ)/TOPAZ (the denominator was arbitrarily chosen), for all coincident pairs. The $-0.9 \%$ mean relative difference suggests an excellent agreement of the averaged ozone column within 6.5 hours between TOPAZ and TROPOZ retrievals.

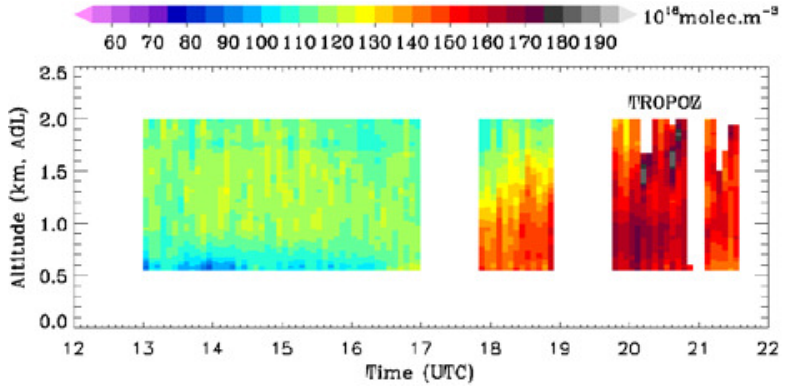

(a)

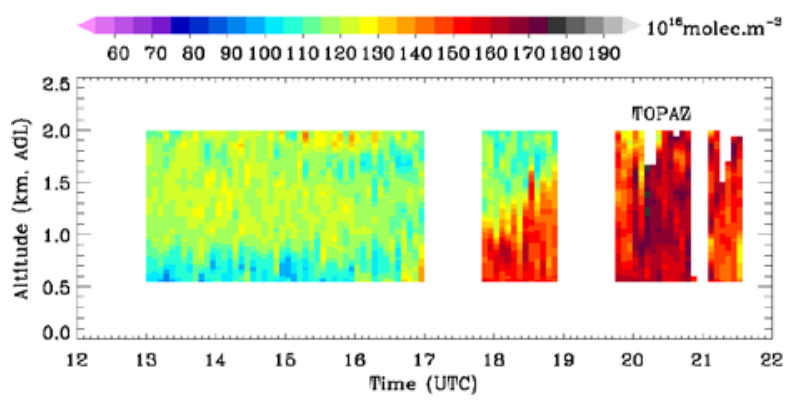

(b)

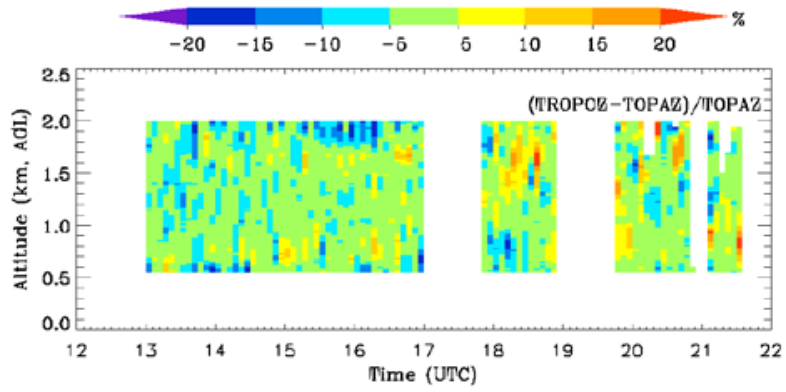

(c)

Figure 1. Comparisons of ozone measured by TROPOZ and TOPAZ. (a) Ozone number densities measured by TROPOZ. (b) Ozone number densities measured by TOPAZ. (c) Their relative percent differences, (TROPOZ-TOPAZ)/TOPAZ.

Figure 2 shows TOPAZ/LMOL intercomparison for the data taken on July 16, 2014 with 1902 coincident pairs from 0.9 to $2 \mathrm{~km}$ and between 1340 to 1730 UTC on this day. The mean ozone values were 97.6 and $101.4 \times 10^{16} \mathrm{molec} \cdot \mathrm{m}^{-3}$ from LMOL and TOPAZ, respectively. Both retrievals coincidentally have the same standard deviation, $15.3 \times 10^{16} \mathrm{molec} \cdot \mathrm{m}^{-3}$. LMOL measured ozone $3.6 \%$ lower than TOPAZ on average with significantly fewer pairs than those from the TROPOZ/TOPAZ comparison. In spite of these measurement differences, the generally random distribution of the relative differences, in Figure $1(\mathrm{c})$ and 2(c), during the large ozone variation 
days, suggest overall consistent measurements from all three lidars.

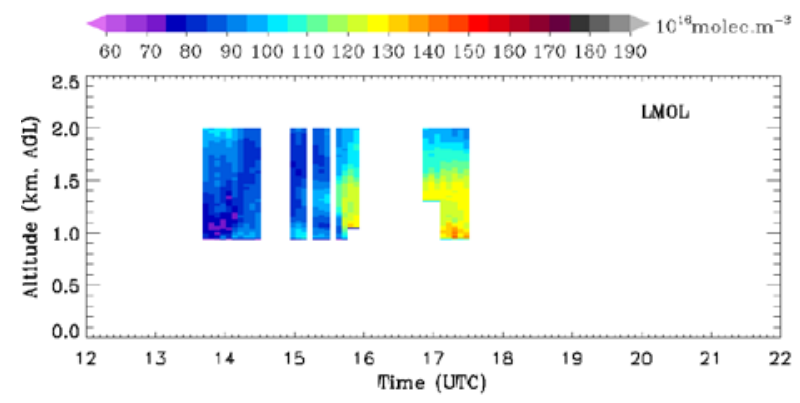

(a)

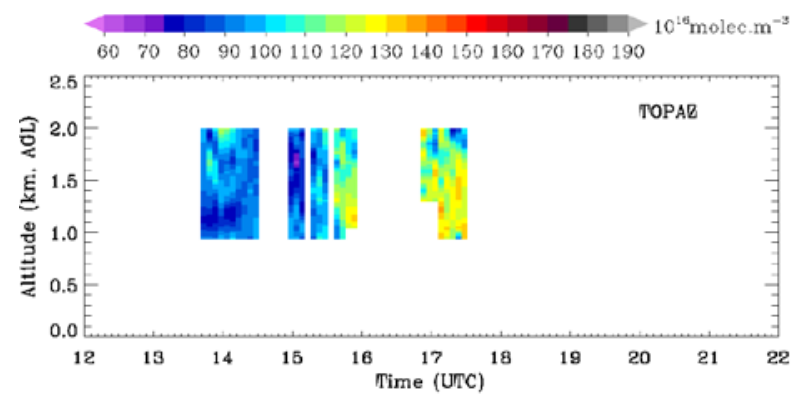

(b)

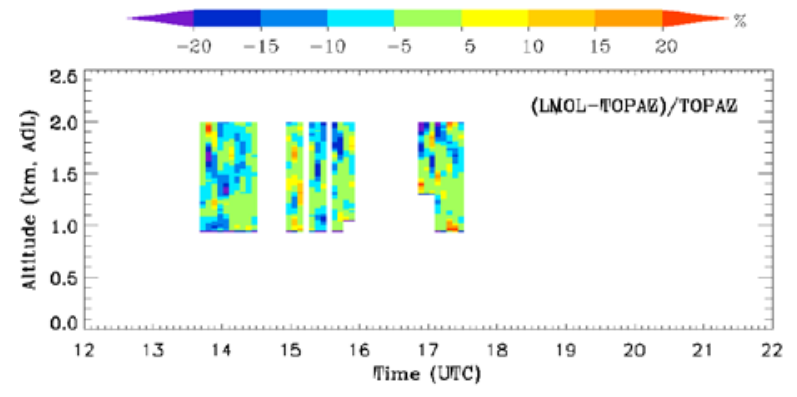

(c)

Figure 2. Comparisons of ozone number densities measured by LMOL and TOPAZ. (a) LMOL-measured ozone. (b) TOPAZ-measured ozone. (c) Their relative percent differences, (LMOL-TOPAZ)/TOPAZ.

\section{CONCLUSIONS}

In this study, intercomparisons between three TOLNet ozone lidars (TROPOZ at NASA's GSFC, TOPAZ at NOAA' ESRL, and LMOL at NASA's LaRC) by using coincident data during the 2014 DISCOVER-AQ and FRAPPÉ campaigns. On average, TROPOZ and TOPAZ reported very similar ozone (within $0.9 \%$ ) while LMOL reported ozone slightly lower (3.6\%) than TOPAZ. The three lidars measured consistent ozone variations evidenced by the lidar curtains and the distribution of their relative difference.

\section{ACKNOWLEDGEMENTS}

This work is supported by the TOLNet program developed by NASA's Science Mission Directorate. The views, opinions, and findings contained in this report are those of the authors and should not be construed as an official NOAA, NASA, or the U.S. Government position, policy, or decision.

\section{References}

[1] Sullivan, J. T., McGee, T. J., DeYoung, R., Twigg, L. W., Sumnicht, G. K., Pliutau, D., Knepp, T., Carrion, W., 2015: Results from the NASA GSFC and LaRC Ozone Lidar Intercomparison: New Mobile Tools for Atmospheric Research, J. Atmos. Oceanic Technol., 32(10), 1779-1795.

[2] Alvarez, R.J., Senff, C.J., Langford, A.O., Weickmann, A.M., Law, D.C., Machol, J.L., Merritt, D.A., Marchbanks, R.D., Sandberg, S.P., Brewer, W.A. and Hardesty, R.M., 2011: Development and application of a compact, tunable, solid-state airborne ozone lidar system for boundary layer profiling, J. Atmos. Oceanic Technol., 28(10), 1258-1272.

[3] Senff, C.J., Alvarez, R.J., Hardesty, R.M., Banta, R.M. and Langford, A.O., 2010: Airborne lidar measurements of ozone flux downwind of Houston and Dallas, J. Geophys. Res., 115, D20307.

[4] Kovalev, V.A. and Bristow, M.P., 1996: Compensational three-wavelength differentialabsorption lidar technique for reducing the influence of differential scattering on ozoneconcentration measurements, Appl. Opt., 35(24), 4790-4797.

[5] De Young, R., Carrion, W., Ganoe, R., Pliutau, D., Gronoff, G., Berkoff, T., Kuang, S., 2017: Langley mobile ozone lidar: ozone and aerosol atmospheric profiling for air quality research, Appl. Opt. 56(3), 721-730.

[6] Papayannis, A., Ancellet, G., Pelon, J., Mégie, G., 1990: Multiwavelength lidar for ozone measurements in the troposphere and the lower stratosphere, Appl. Opt., 29(4), 467-476. 